ORIGINAL ARTICLE

\title{
Symptoms and medical conditions in Australian veterans of the 1991 Gulf War: relation to immunisations and other Gulf War exposures
}

\author{
H L Kelsall, M R Sim, A B Forbes, D C Glass, D P McKenzie, J F Ikin, M J Abramson, L Blizzard, \\ P Ittak
}

Occup Environ Med 2004;61:1006-1013. doi: 10.1136/oem.2003.009258

See end of article for authors' affiliations

Correspondence to Dr H Kelsall, Department of Epidemiology and Preventive Medicine, Monash University-Central and Eastern Clinical School, Alfred Hospital, Commercial Road, Melbourne, VIC 3004 Australia; helen.kelsall@ med.monash.edu.au

Accepted 6 June 2004

\begin{abstract}
Aims: To investigate whether Australian Gulf War veterans have a higher than expected prevalence of recent symptoms and medical conditions that were first diagnosed in the period following the 1991 Gulf War; and if so, whether these effects were associated with exposures and experiences that occurred in the Gulf War.

Methods: Cross-sectional study of 1456 Australian Gulf War veterans and a comparison group who were in operational units at the time of the Gulf War, but were not deployed to that conflict ( $n=1588$ ). A postal questionnaire was administered and the likelihood of the diagnosis of self-reported medical conditions was assessed and rated by a medical practitioner.

Results: Gulf War veterans had a higher prevalence of all self-reported health symptoms than the comparison group, and more of the Gulf War veterans had severe symptoms. Increased symptom reporting was associated with several exposures, including having more than 10 immunisations, pyridostigmine bromide tablets, anti-biological warfare tablets, pesticides, insect repellents, reportedly being in a chemical weapons area, and stressful military service experiences in a strong dose-response relation. Gulf War veterans reported psychological (particularly post-traumatic stress disorder), skin, eye, and sinus conditions first diagnosed in 1991 or later more commonly than the comparison group. Over $90 \%$ of medical conditions reported by both study groups were rated by a medical practitioner as having a high likelihood of diagnosis.

Conclusion: More than 10 years after the 1991 Gulf War, Australian veterans self-report all symptoms and some medical conditions more commonly than the comparison group. Further analysis of the severity of symptoms and likelihood of the diagnosis of medical conditions suggested that these findings are not due to over-reporting or to participation bias.
\end{abstract}

n the 1991 Gulf War, Australia deployed 1871 Australian Defence Force personnel to the Gulf area as part of a larger multinational response to the invasion of Kuwait by Iraq on 2 August 1990.

Since 1992 there has been a sustained international effort to investigate the health complaints of Gulf War veterans, with self-reported symptoms, medical conditions, and other general health outcomes measured in postal or telephone surveys conducted through cross-sectional studies of Gulf War veterans from the UK, ${ }^{1-3}$ the USA ${ }^{4-8}$ Denmark, ${ }^{9}$ and Canada. ${ }^{10}$ A common finding of these studies is that health problems such as self-reported symptoms, medical conditions, functional impairment, and perception of poor health are more common among Gulf War veterans than their military comparison groups; and that adverse health outcomes are associated with a number of Gulf War exposures including immunisations, smoke from oil well fires, pyridostigmine bromide, pesticides, and stressful experiences.

Gulf War health research has done much to clarify the health problems of Gulf War veterans, but has had some limitations. ${ }^{11-13}$ These limitations have included health outcomes and exposure data based solely or mainly on selfreport, self-referred populations in registry studies, problems in objectively measuring exposures, and difficulties locating and contacting study participants. Typically, participation by the non-deployed comparison groups have been low, ${ }^{14} 91014$ rendering the results of these studies vulnerable to participation bias.
The current study investigated whether Australian Gulf War veterans have a higher than expected prevalence of selfreported symptoms and of medical conditions that were first diagnosed in the period since the Gulf War. If adverse health effects were found to be higher in Gulf War veterans, associations with exposures and experiences that occurred in the Gulf War were explored. In addition, the characteristics of self-reported symptoms and medical conditions, and the effect of possible participation bias, were investigated further.

\section{METHODS}

The study was approved by the Standing Committee on Ethics in Research Involving Humans at Monash University, the Department of Veterans' Affairs (DVA) Human Research Ethics Committee, and the Australian Defence Human Research Ethics Committee.

\section{Study population}

The study population was the entire cohort of 1871 Australian veterans who served in the Gulf region during the period from 2 August 1990 to 4 September 1991. A comparison group of 2924 subjects was randomly selected

Abbreviations: ADF, Australian Defence Force; adj OR, adjusted odds ratio; DU, depleted uranium; DVA, Department of Veterans' Affairs; HSA, Health Services Australia; MSE questionnaire, Military Service Experience questionnaire; OR, odds ratio; PTSD, post-traumatic stress disorder; SD, standard deviation; SF-12, 12-item version of the ShortForm Health Survey 


\section{Main messages}

- Australian Gulf War veterans report all symptoms more commonly than expected, and more of the Gulf War veterans report symptoms that are more severe in nature.

- Australian Gulf War veterans report psychological (particularly post-traumatic stress disorder), skin, eye, and sinus conditions more commonly than expected.

- The likelihood of the diagnosis of self-reported medical conditions is high in both study groups, and increased reporting of medical conditions by Gulf War veterans does not appear to be explained by over-reporting.

- Increased symptom reporting in Gulf War veterans is associated with several medical, environmental, and chemical exposures and stressful military service experiences reported in relation to the 1991 Gulf War.

from 26411 Australian Defence Force (ADF) personnel who were in operational units at the time of the Gulf War, but were not deployed to that conflict. They were frequency matched to the Gulf War group by service type, sex, and three year age band, and additionally by officer/non-officer status within the Army subgroup and by aircrew/non-aircrew status within the Air Force subgroup. The comparison group was over-sampled in anticipation of lower participation within this group.

\section{Recruitment}

Recruitment commenced in August 2000 and concluded in April 2002. Subjects were recruited via mailed invitations with two further mailings and follow up phone contact for non-responders. Measures to maximise participation included personally addressed invitations to participate, a letter of endorsement from the Minister for Veterans' Affairs, and reimbursement of expenses or income lost as a result of participation. Last known addresses were obtained from several databases including those of DVA and Department of Defence, the electoral roll, health authorities, and telephone directories.

\section{Data collection}

Participation in the study included completing a postal questionnaire and undergoing a comprehensive health assessment which was carried out by specially trained doctors, nurses, and psychologists at 10 Health Services Australia (HSA) clinics located around Australia. Some subjects, who were unable or unwilling to attend the health assessment, completed the postal questionnaire only.

\section{Instruments}

The self-administered postal questionnaire asked about demographic and military service details, exposure history, tobacco use, alcohol consumption, health symptoms, and medical conditions.

The 63 item self-report symptom questionnaire asked about the occurrence of symptoms in the past month, and whether the severity of those symptoms was "mild", "moderate", or "severe". The 58 item medical condition questionnaire asked about problems or conditions that had been diagnosed or treated by a medical doctor, and the year in which the condition was first diagnosed. The symptom and medical questionnaires were based on those used by Unwin and colleagues, ${ }^{1}$ but included additional items considered relevant to Australian veterans.

\section{Policy implications}

- Efforts should be made to ensure that record keeping in relation to immunisations and other exposures experienced during deployment is complete.

- Defence health services should ensure that there is optimal preparation for deployment, means are in place to detect increased symptom or medical conditions reporting in returning veterans, and treatment facilities are available for medical conditions we found to be in excess.

Gulf War veterans were asked to refer to their immunisation booklet, if available, for details about the total number of immunisations received, the timing of these in relation to their Gulf War deployment, the time period over which they received them, and the individual immunisations received. Veterans were also asked about the duration and quantity of any anti-nerve agent (pyridostigmine bromide) tablets taken, and the duration in days of any antimalarial or antibiological warfare tablets taken. A 28 item chemical and environmental exposure questionnaire asked veterans to identify exposures that they experienced during the Gulf War including dust storms, intense smoke from burning oil wells, pesticides, insect repellents, being in an area where chemical warfare agents had probably been used, and possible exposure to depleted uranium.

In investigating the relation between self-reported exposures and total number of symptoms in Gulf War veterans, possible exposure to depleted uranium was defined on the basis of whether the veteran was in Camp Doha, Kuwait when the tank compound caught fire or was involved in the subsequent clean up operations, or if they reported either using depleted uranium munitions or entering or inspecting destroyed enemy equipment and had been in either Kuwait or in the battle zone areas. DVA Nominal Roll deployment information was used to group veterans according to whether their deployment was completed before or after the commencement of the air war against Iraq on 17 January 1991. A cluster of immunisations was defined as more than five immunisations within one week or less.

Exposure to psychological stressors during the Gulf War was measured using the 44 item Military Service Experience (MSE) questionnaire which was developed specifically for this study ${ }^{15}$ as existing war-stress questionnaires appeared to inadequately explore the experiences of navy groups in particular. Themes included fear and threat of injury or death or attack, including the threat of nuclear, biological, or chemical attack, feelings of helplessness and lack of control, poor preparation, malevolent environment, lack of support, and lack of unit cohesion. The instrument was derived from various sources including the findings from a focus group of Australian Gulf War veterans and modified items from preexisting combat exposure questionnaires. ${ }^{16-20}$ The MSE questionnaire was scored by summing the number of positive responses, providing a score range of 0 to 44 .

During the medical assessment, the HSA doctor, who was blinded to the Gulf War status of the participant, asked the subject further questions about each reported medical condition and classified the self-reported diagnosis as "nonmedical" if the condition had not been diagnosed or treated by a medical doctor. If the reported condition had been diagnosed or treated by a medical doctor, the likelihood of the diagnosis was classified as "unlikely", "possible", or "probable" according to specified criteria that related to consistency of history of the condition with the diagnosis, 
and whether confirmatory investigations, treatment, or specialist referral had been undertaken by the person's doctor in relation to the condition. This was done to improve the accuracy of the classification of these self-reported diagnoses.

\section{Statistical methods}

Statistical analyses were performed using Stata version $7 .^{21}$ Associations between Gulf War deployment and symptoms and medical conditions, adjusting for potentially confounding factors, were assessed using logistic regression ${ }^{22}$ and reported as adjusted prevalence odds ratios (adj OR) with $95 \%$ confidence intervals (95\% CI). In the analysis of medical conditions first diagnosed in 1991 or later, medical conditions that were first diagnosed in 1990 or earlier (that is, prior to the Gulf War) were excluded from the analysis. Where less than five subjects in either study group experienced the outcome of interest, exact logistic regression was performed. ${ }^{23}$ Likelihood ratio tests ${ }^{22}$ were performed to investigate homogeneity of the effects of study group across categories of age, rank, and service type for total symptom count. These were performed using interaction terms added to the logistic regression model. The ratio of means for total symptom count and total number of medical conditions were adjusted for possible confounders by negative binomial regression, which is a statistical technique that allows for greater dispersion of counted values than does a Poisson regression..$^{24}$ The ratio of means is reported as this is a natural summary measure for analysis of counts using negative binomial regression. ${ }^{25}$ The values of the crude, and the adjusted, odds ratios and ratio of means were found to be highly similar, and so only the adjusted results are reported.

To explore the relation between total symptom count and Gulf War related exposure to immunisations, psychological stressors, pyridostigmine bromide, and antimalarial and antibiological warfare tablets in Gulf War veterans, exposureresponse trends were computed using the number of immunisations and the MSE questionnaire score as linear variables and the number of pyridostigmine bromide tablets taken (none, 1-80, 81-180, >180 tablets), and the number of days antimalarial and anti-biological warfare tablets were taken (none, 1-30, 31-90, >90 days of tablets taken) as categorical variables in the relevant regressions.

To investigate the possible effects of participation bias on our results, we collected brief demographic and health status (Short-Form 12 (SF-12) Health Survey ${ }^{26}$ ) data from a telephone survey of non-participants. Study participants who completed the postal questionnaire also completed the SF-12. A prediction model was used to compute age, rank, and service adjusted odds ratios for the relative health outcomes of Gulf War veterans versus comparison group subjects, as if the study had achieved full participation. The predicted "full participation" adjusted odds ratios were averaged over 100 replications of the analyses, as described previously. ${ }^{15}$

\section{RESULTS}

\section{Participation}

From the original study sample of 1871 Gulf War veterans, $1456(80.5 \%)$ of 1808 recruitable (not reportedly deceased or overseas) subjects participated, including 1414 (78.2\%) who completed the health assessment and postal questionnaire, and $42(2.3 \%)$ who completed the postal questionnaire alone. Of the 2924 comparison group subjects, 1588 (56.8\%) of 2796 recruitable subjects participated, with 1411 (50.5\%) completing the health assessment and postal questionnaire, and $177(6.3 \%)$ completing the postal questionnaire alone.

\section{Demographic characteristics}

Due to the very small number of female veterans, the analyses were limited to male subjects. Demographic and socioeconomic characteristics of male participants have been reported previously. ${ }^{15}$ Among male subjects who completed the postal questionnaire, Gulf War veterans were slightly younger than comparison group participants, more likely to have served in the Navy, been of lower rank, and less likely to have a tertiary education-that is, an undergraduate or postgraduate degree. There were no differences in other demographic or socioeconomic characteristics of participants. Subjects who were younger and of lower rank were least likely to participate in both study groups. Air Force subjects were least likely to participate in the Gulf War veteran group, and most likely to participate in the comparison group.

Investigation of possible effects of participation bias The telephone survey for non-participants, on which part of the prediction model for assessing possible participation bias was based, was completed by approximately one quarter $(n=411)$ of all study non-participants, and the prediction model assumed that the telephone respondents' answers were representative of those of the remainder of the nonparticipants.

The predicted full participation adjusted odds ratio for selfreported fatigue in the past month was 1.36 , which was only marginally lower than the observed odds ratio of 1.42 found among participants. For doctor diagnosed back/neck problems and doctor diagnosed post-traumatic stress disorder (PTSD), the corresponding results were 0.97 (predicted) versus 0.99 (observed), and 2.85 (predicted) versus 2.86 (observed), respectively.

\section{Symptoms}

The pattern of symptom reporting (fig 1) shows that Gulf War veterans reported all 63 symptoms more commonly than the comparison group, and all but seven of the differences were statistically significant. Table 1 shows the results for the 15 most frequently reported symptoms in the past month. When the analysis was confined to moderate or severe symptoms, most of the odds ratios increased, indicating that more Gulf War veterans reported severe symptoms.

The mean total number of self-reported symptoms was significantly higher for Gulf War veterans (table 2). The differences across subgroups of age and rank approached statistical significance, with higher symptom reporting in younger veterans and in more junior ranks.

\section{Medical conditions first diagnosed in 1991 or later}

Of the 15 most commonly self-reported medical conditions in the Gulf War veteran group, shown in table 3, the most commonly reported were musculoskeletal, skin, and psychological conditions. Increased reporting in Gulf War veterans

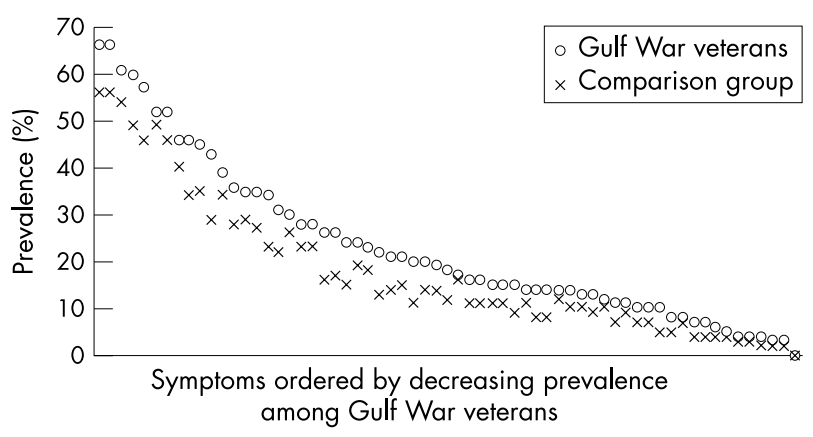

Figure 1 Pattern of self-reported symptoms in the past month by Gulf War deployment status. 
Table 1 Prevalences, odds ratios (OR), and $95 \%$ confidence intervals $(95 \% \mathrm{Cl})$ of the 15 most frequently self-reported symptoms in the past month ordered by decreasing prevalence in the Gulf War group

\begin{tabular}{|c|c|c|c|c|c|c|c|c|}
\hline \multirow[b]{2}{*}{ Symptom } & \multicolumn{4}{|c|}{ All symptoms whether "mild, moderate, or severe" } & \multicolumn{4}{|c|}{ "Moderate or severe" symptoms only } \\
\hline & $\begin{array}{l}\text { Gulf War } \\
\text { veterans } \\
\text { n (\%) }\end{array}$ & $\begin{array}{l}\text { Comparison } \\
\text { group } \\
\text { n (\%) }\end{array}$ & Adj OR* & $95 \% \mathrm{Cl}$ & $\begin{array}{l}\text { Gulf War } \\
\text { veterans } \\
\text { n (\%) }\end{array}$ & $\begin{array}{l}\text { Comparison } \\
\text { group } \\
\mathrm{n}(\%)\end{array}$ & Adj $O R^{*}$ & $95 \% \mathrm{Cl}$ \\
\hline Feeling unrefreshed after sleep & $937(66)$ & $862(56)$ & 1.6 & 1.3 to 1.8 & $398(28)$ & $285(18)$ & 1.7 & 1.4 to 2.1 \\
\hline Fatigue & $937(66)$ & $861(56)$ & 1.6 & 1.3 to 1.8 & $325(23)$ & $243(16)$ & 1.6 & 1.3 to 1.9 \\
\hline Headaches & $872(61)$ & $828(54)$ & 1.3 & 1.1 to 1.6 & $291(20)$ & 205 (13) & 1.6 & 1.3 to 2.0 \\
\hline Sleeping difficulties & $851(60)$ & $753(49)$ & 1.6 & 1.4 to 1.9 & $371(26)$ & $253(16)$ & 1.8 & 1.5 to 2.2 \\
\hline Irritability/outbursts of anger & $808(57)$ & $702(46)$ & 1.6 & 1.4 to 1.8 & $309(22)$ & $182(12)$ & 2.0 & 1.7 to 2.5 \\
\hline Low back pain & $743(52)$ & $757(49)$ & 1.2 & 1.0 to 1.3 & $308(22)$ & $298(19)$ & 1.2 & 1.0 to 1.4 \\
\hline General muscle aches or pains & $736(52)$ & $707(46)$ & 1.3 & 1.1 to 1.5 & 207 (15) & $139(9)$ & 1.7 & 1.4 to 2.2 \\
\hline Flatulence or burping & $654(46)$ & $624(40)$ & 1.3 & 1.1 to 1.5 & 209 (15) & $141(9)$ & 1.6 & 1.3 to 2.1 \\
\hline Forgetfulness & $654(46)$ & $520(34)$ & 1.7 & 1.5 to 2.0 & 195 (14) & $109(7)$ & 2.1 & 1.6 to 2.7 \\
\hline Difficulty finding the right word & $643(45)$ & $543(35)$ & 1.6 & 1.4 to 1.8 & $160(11)$ & $82(5)$ & 2.3 & 1.7 to 3.0 \\
\hline Loss of concentration & $611(43)$ & $448(29)$ & 1.9 & 1.6 to 2.3 & $144(10)$ & $78(5)$ & 2.2 & 1.6 to 2.9 \\
\hline Stiffness in several joints & $556(39)$ & $518(34)$ & 1.3 & 1.1 to 1.5 & $215(15)$ & $175(11)$ & 1.4 & 1.2 to 1.8 \\
\hline Rash or skin irritation & $510(36)$ & 429 (28) & 1.5 & 1.2 to 1.7 & 215 (15) & $129(8)$ & 2.0 & 1.6 to 2.5 \\
\hline $\begin{array}{l}\text { Pain, without swelling or } \\
\text { redness, in several joints }\end{array}$ & $498(35)$ & $453(29)$ & 1.3 & 1.1 to 1.5 & $231(16)$ & $197(13)$ & 1.3 & 1.1 to 1.6 \\
\hline Itchy or painful eyes & $490(35)$ & $424(27)$ & 1.4 & 1.2 to 1.7 & $115(8)$ & $88(6)$ & 1.4 & 1.1 to 1.9 \\
\hline
\end{tabular}

was statistically significant for about half of these conditions, and the strongest association was for post-traumatic stress disorder (PTSD). When the analysis was confined to conditions that had been rated as a "possible" or "probable" diagnosis, the results were very similar (table 3).

Gulf War veterans reported a $20 \%$ higher mean total number of conditions first diagnosed in 1991 or later (mean (SD) $2.4(2.4) v 2.0(2.0)$, adjusted ratio of means 1.2 (95\% CI 1.1 to 1.3$), \mathrm{p}<0.001$ ), as well as a $20 \%$ higher mean total number of "possible" or "probable" conditions first diagnosed in 1991 or later (mean $2.2(2.2) v 1.9$ (1.8), adjusted ratio of means 1.2 (95\% CI 1.1 to 1.3$), \mathrm{p}<0.001)$.

The results of the medical assessment of the likelihood of the diagnosis showed that of the medical conditions reported by Gulf War veterans, $91.3 \%$ were medically assessed to be "possible" or "probable" diagnoses, which was a little lower than the $93.2 \%$ of the comparison group.

\section{Gulf War exposures}

Of 1418 Gulf War veteran subjects, 726 (51.2\%) indicated that they had their immunisation booklets to refer to. Veterans who had their immunisation booklets reported higher numbers of immunisations, and were also less likely to report that they had not received any immunisations, than subjects who did not have their immunisation booklets (data not shown).

Table 4 shows that the total number of health symptoms self-reported in the past month by Gulf War veterans was

Table 2 Association between total number of self-reported symptoms and service type, rank, and age

\begin{tabular}{|c|c|c|c|c|}
\hline & \multicolumn{4}{|c|}{ Total number of symptoms } \\
\hline & $\begin{array}{l}\text { Gulf War } \\
\text { veterans } \\
\text { Mean (SD) }\end{array}$ & $\begin{array}{l}\text { Comparison } \\
\text { group } \\
\text { Mean (SD) }\end{array}$ & $\begin{array}{l}\text { Adjusted ratio of } \\
\text { means }(95 \% \mathrm{Cl})^{*}\end{array}$ & $p$ value \\
\hline Total study population & $14.7(11.1)$ & $11.3(9.2)$ & $1.3(1.2$ to 1.4$)$ & $<0.001$ \\
\hline \multicolumn{5}{|l|}{ Subgroup (at Gulf War) } \\
\hline \multicolumn{5}{|l|}{ Service type } \\
\hline Navy & $14.9(11.2)$ & $11.2(9.3)$ & 1.3 (1.3 to 1.4$)$ & $0.164 \dagger$ \\
\hline Army & $16.6(11.6)$ & $14.1(9.8)$ & $1.1(1.0$ to 1.4$)$ & \\
\hline Air Force & $11.4(9.7)$ & $9.5(8.0)$ & $1.2(1.0$ to 1.5$)$ & \\
\hline \multicolumn{5}{|l|}{ Rank } \\
\hline Officer & $11.0(8.5)$ & $8.8(7.9)$ & $1.3(1.1$ to 1.5$)$ & $0.087 \dagger$ \\
\hline Other ranks-supervisory $\ddagger$ & $15.1(11.2)$ & $12.5(9.4)$ & $1.3(1.2$ to 1.4$)$ & \\
\hline Other ranks-non-supervisory & $16.3(11.9)$ & $11.4(9.6)$ & $1.5(1.3$ to 1.6$)$ & \\
\hline \multicolumn{5}{|l|}{ Age } \\
\hline$<20$ years & $16.2(11.7)$ & $9.8(8.6)$ & $1.6(1.4$ to 2.0$)$ & $0.063 \dagger$ \\
\hline $20-24$ years & $14.5(11.1)$ & $10.8(9.1)$ & $1.3(1.2$ to 1.5$)$ & \\
\hline $25-34$ years & $14.9(10.9)$ & $11.2(8.7)$ & $1.3(1.2$ to 1.4$)$ & \\
\hline$\geqslant 35$ years & $14.9(11.5)$ & $13.0(10.9)$ & $1.2(1.0$ to 1.4$)$ & \\
\hline
\end{tabular}

*Ratios of means are adjusted for service type, rank, age $(<20,20-24,25-34, \geqslant 35$ years), education, and marital status by negative binomial regression.

$\mathrm{tp}$ values shown for service type, rank, and age result from a test of whether the ratio of the mean total number of symptoms between Gulf War veterans and the comparison group are the same at each level of service type, rank, or age.

f"Other ranks-supervisory" includes all non-commissioned officer ranks. These ranks were considered to hold supervisory positions, with the lowest rank being Leading Seamen in the Navy and Corporal in the Army and Air Force. 
Table 3 Prevalences, odds ratios (OR), and $95 \%$ confidence intervals $(95 \% \mathrm{Cl}$ ) of the 15 most frequently self-reported doctor diagnosed or treated medical conditions first diagnosed in 1991 or later

\begin{tabular}{|c|c|c|c|c|c|c|c|c|}
\hline \multirow[b]{2}{*}{ Medical condition } & \multicolumn{4}{|c|}{ First diagnosed in 1991 or later } & \multicolumn{4}{|c|}{$\begin{array}{l}\text { First diagnosed in } 1991 \text { or later and rated as a } \\
\text { "possible or probable" diagnosis* }\end{array}$} \\
\hline & $\begin{array}{l}\text { Gulf War } \\
\text { veterans } \\
\text { n (\%) }\end{array}$ & $\begin{array}{l}\text { Comparison } \\
\text { group } \\
\text { n (\%) }\end{array}$ & $\begin{array}{l}\text { Adj } \\
\text { ORt }\end{array}$ & $95 \% \mathrm{Cl}$ & $\begin{array}{l}\text { Gulf War } \\
\text { veterans } \\
\text { n (\%) }\end{array}$ & $\begin{array}{l}\text { Comparison } \\
\text { group } \\
\text { n (\%) }\end{array}$ & $\begin{array}{l}\text { Adi } \\
\text { ORt }\end{array}$ & $95 \% \mathrm{Cl}$ \\
\hline Back or neck problems & $353(29)$ & $370(30)$ & 1.0 & 0.8 to 1.2 & $307(26)$ & $294(27)$ & 1.0 & 0.8 to 1.2 \\
\hline Joint problems & $279(22)$ & $262(20)$ & 1.2 & 1.0 to 1.5 & $245(20)$ & $222(19)$ & 1.1 & 0.9 to 1.4 \\
\hline $\begin{array}{l}\text { Skin problem other than dermatitis, } \\
\text { eczema, psoriasis, skin cancer, } \\
\text { or malignant melanoma }\end{array}$ & $207(16)$ & $172(12)$ & 1.4 & 1.1 to 1.7 & $176(14)$ & $141(11)$ & 1.3 & 1.1 to 1.7 \\
\hline Anxiety, stress, or depression & $203(15)$ & $184(12)$ & 1.3 & 1.0 to 1.6 & $177(13)$ & $155(12)$ & 1.2 & 1.0 to 1.5 \\
\hline Hearing loss & $185(14)$ & $201(14)$ & 1.0 & 0.8 to 1.2 & $170(13)$ & $172(14)$ & 1.0 & 0.8 to 1.2 \\
\hline Eye or vision problems, e.g. glaucoma & 165 (13) & $137(10)$ & 1.4 & 1.1 to 1.7 & $145(11)$ & $108(9)$ & 1.4 & 1.2 to 1.8 \\
\hline $\begin{array}{l}\text { Bowel disorder, e.g. diarrhoea, } \\
\text { constipation, bleeding }\end{array}$ & $153(11)$ & $142(10)$ & 1.1 & 0.9 to 1.4 & $131(10)$ & $121(10)$ & 1.1 & 0.8 to 1.4 \\
\hline Sinus problems & $136(11)$ & $100(7)$ & 1.5 & 1.1 to 2.0 & $122(10)$ & $81(7)$ & 1.5 & 1.1 to 2.0 \\
\hline High blood pressure & $127(9)$ & $120(8)$ & 1.2 & 0.9 to 1.6 & $105(8)$ & $96(7)$ & 1.2 & 0.9 to 1.6 \\
\hline Skin cancer other than malignant melanoma & $103(8)$ & $137(9)$ & 0.9 & 0.7 to 1.2 & $92(7)$ & $110(8)$ & 1.0 & 0.7 to 1.3 \\
\hline Ear infection & $102(8)$ & $98(7)$ & 1.1 & 0.8 to 1.5 & $96(8)$ & $88(7)$ & 1.1 & 0.8 to 1.5 \\
\hline Dermatitis & $102(8)$ & $66(5)$ & 1.7 & 1.2 to 2.4 & $87(7)$ & $52(4)$ & 1.8 & 1.3 to 2.6 \\
\hline Hay fever & $102(8)$ & $89(7)$ & 1.3 & 1.0 to 1.8 & $84(7)$ & $75(6)$ & 1.2 & 0.8 to 1.7 \\
\hline $\begin{array}{l}\text { Psychiatric or psychological condition other } \\
\text { than alcohol or drug abuse or dependency, } \\
\text { anxiety, stress, depression, or post-traumatic } \\
\text { stress disorder }\end{array}$ & $75(5)$ & $79(5)$ & 1.0 & 0.7 to 1.4 & $57(4)$ & $64(5)$ & 0.9 & 0.6 to 1.3 \\
\hline Post-traumatic stress disorder & $70(5)$ & $31(2)$ & 3.1 & 2.0 to 4.9 & $61(4)$ & $24(2)$ & 3.4 & 2.0 to 5.6 \\
\hline
\end{tabular}

associated with increasing numbers of immunisations in a dose-response relation, indicating that there is an expected increase of $4 \%$ in the expected number of symptoms reported per each additional immunisation received among those reporting at least one immunisation. The total number of symptoms was associated with having at least 10 immunisations, but not with having any immunisations or with having a cluster of immunisations. The total number of symptoms was also greater in those who reported that they did not know the number of immunisations they received.

Table 5 shows that the total number of health symptoms self-reported in the past month was associated with several other Gulf War exposures. These exposures included taking pyridostigmine bromide or anti-biological warfare tablets, exposure to pesticides, using insect repellents, and reportedly being in a chemical weapons area. The total number of health symptoms was associated with an increasing number of days that anti-biological warfare tablets were taken, in a dose-response relation, and with increasing numbers of stressful military service experiences during the Gulf War, as measured by an increasing MSE questionnaire score, in a strong dose-response relation. The total number of symptoms was also greater in those who reported that they did not know whether they had received medications such as pyridostigmine bromide or anti-biological warfare tablets. There was no association with other exposures such as taking antimalarials or possible exposure to depleted uranium.

\section{DISCUSSION}

Our study has found that Australian Gulf War veterans reported significantly more health symptoms than ADF personnel who did not deploy to the 1991 Gulf War. The medical conditions with the largest associations with Gulf War service included post-traumatic stress disorder and skin

Table 4 Association of Gulf War veterans' total number of health symptoms with reported number of immunisations received in relation to their Gulf War deployment

\begin{tabular}{|c|c|c|c|c|c|}
\hline \multirow[b]{2}{*}{ Immunisations } & \multicolumn{5}{|c|}{ Total number of health symptoms } \\
\hline & $\mathbf{n}$ & Mean & (SD) & $\begin{array}{l}\text { Adj ratio of } \\
\text { means* }\end{array}$ & $95 \% \mathrm{Cl}$ \\
\hline None & 119 & 13.8 & (11.1) & 1.0 & - \\
\hline Any & 956 & 14.0 & (10.7) & 1.0 & 0.9 to 1.2 \\
\hline $1-4$ & 267 & 11.6 & (8.8) & 0.9 & 0.7 to 1.0 \\
\hline $5-9$ & 563 & 14.1 & (10.8) & 1.0 & 0.9 to 1.2 \\
\hline 10 or more & 126 & 18.8 & (12.4) & 1.3 & 1.1 to 1.6 \\
\hline Dose response in those $\geqslant 1 \dagger$ & - & - & - & 1.04 & 1.03 to 1.06 \\
\hline Don't know & 342 & 16.9 & (12.0) & 1.2 & 1.0 to 1.4 \\
\hline Cluster of immunisations - nonef & 962 & 14.1 & (10.8) & 1.0 & - \\
\hline Cluster of immunisations - any & 150 & 14.8 & $(11.6)$ & 1.1 & 1.0 to 1.2 \\
\hline \multicolumn{6}{|c|}{$\begin{array}{l}\text { *Ratios of means are adjusted for service type, rank, age }(<20,20-24,25-34, \geqslant 35 \text { years), education, and } \\
\text { marital status by negative binomial regression. } \\
\dagger \text { Dose-response per unit increase in number of immunisations in those who had received at least one immunisation } \\
(p<0.001) \text {. } \\
\ddagger A \text { cluster of immunisations was defined as }>5 \text { immunisations within one week or less. }\end{array}$} \\
\hline
\end{tabular}


Table 5 Association of Gulf War veterans' total number of health symptoms with reported Gulf War exposures and experiences

\begin{tabular}{|c|c|c|c|c|c|}
\hline \multirow[b]{2}{*}{ Gulf War exposure } & \multicolumn{5}{|c|}{ Total number of health symptoms } \\
\hline & n & Mean & (SD) & $\begin{array}{l}\text { Adj ratio of } \\
\text { means* }\end{array}$ & $95 \% \mathrm{Cl}$ \\
\hline \multicolumn{6}{|c|}{$\begin{array}{l}\text { Deployment completed before air war on } \\
17 \text { January } 1991\end{array}$} \\
\hline Yes & 331 & 13.3 & $(10.0)$ & 1.0 & - \\
\hline No & 1089 & 15.1 & (11.4) & 1.1 & 1.0 to 1.2 \\
\hline \multicolumn{6}{|l|}{ MSE questionnaire score } \\
\hline $0-4$ & 320 & 8.7 & (7.4) & 1.0 & - \\
\hline $5-8$ & 414 & 11.5 & (8.5) & 1.3 & 1.2 to 1.5 \\
\hline $9-12$ & 316 & 15.8 & (10.1) & 1.8 & 1.6 to 2.0 \\
\hline$>12$ & 368 & 22.6 & (12.5) & 2.5 & 2.3 to 2.8 \\
\hline Dose-response $†$ & - & - & - & 1.07 & 1.06 to 1.07 \\
\hline \multicolumn{6}{|l|}{ Pyridostigmine bromide } \\
\hline None & 371 & 11.2 & $(8.7)$ & 1.0 & - \\
\hline Any & 726 & 15.8 & (11.7) & 1.4 & 1.2 to 1.5 \\
\hline $1-80$ tablets taken & 152 & 14.3 & (11.6) & 1.3 & 1.1 to 1.5 \\
\hline $81-180$ tablets taken & 156 & 16.9 & (12.0) & 1.4 & 1.2 to 1.6 \\
\hline$>180$ tablets taken & 148 & 16.9 & (12.5) & 1.4 & 1.2 to 1.7 \\
\hline Dose-response§ & - & - & - & 1.1 & 1.1 to 1.2 \\
\hline Don't know & 318 & 16.3 & (11.6) & 1.4 & 1.2 to 1.6 \\
\hline \multicolumn{6}{|l|}{ Antimalarials } \\
\hline None & 283 & 12.9 & $(10.1)$ & 1.0 & - \\
\hline Any & 586 & 14.8 & (11.6) & 1.1 & 1.0 to 1.2 \\
\hline 1-30 days of tablets taken & 191 & 13.0 & (10.7) & 1.0 & 0.8 to 1.1 \\
\hline 31-90 days of tablets taken & 130 & 13.2 & (10.7) & 1.0 & 0.8 to 1.2 \\
\hline$>90$ days of tablets taken & 108 & 15.8 & (10.7) & 1.2 & 1.0 to 1.4 \\
\hline Dose-response§ & - & - & - & 1.0 & 1.0 to 1.1 \\
\hline Don't know & 543 & 15.6 & (11.1) & 1.1 & 1.0 to 1.2 \\
\hline \multicolumn{6}{|l|}{ Anti-biological warfare tablets } \\
\hline None & 540 & 11.4 & (9.6) & 1.0 & - \\
\hline Any & 81 & 19.4 & (13.6) & 1.6 & 1.4 to 1.9 \\
\hline 1-30 days of tablets taken & 25 & 16.4 & (15.7) & 1.4 & 0.9 to 2.0 \\
\hline 31-90 days of tablets taken & 22 & 17.8 & (8.4) & 1.6 & 1.3 to 2.1 \\
\hline$>90$ days of tablets taken & 12 & 22.8 & (12.7) & 1.9 & 1.4 to 2.5 \\
\hline Dose-response§ & - & - & - & 1.3 & 1.2 to 1.4 \\
\hline Don't know & 792 & 16.5 & (11.3) & 1.4 & 1.3 to 1.5 \\
\hline \multicolumn{6}{|l|}{ Pesticides } \\
\hline No & 1035 & 13.4 & (10.4) & 1.0 & - \\
\hline Yes & 366 & 18.5 & (12.5) & 1.3 & 1.2 to 1.4 \\
\hline \multicolumn{6}{|l|}{ Insect repellents } \\
\hline No & 862 & 14.1 & $(11.0)$ & 1.0 & - \\
\hline Yes & 503 & 16.0 & (11.4) & 1.2 & 1.1 to 1.3 \\
\hline \multicolumn{6}{|l|}{ Chemical weapons area } \\
\hline No & 1252 & 14.1 & $(10.7)$ & 1.0 & - \\
\hline Yes & 152 & 19.4 & (13.0) & 1.3 & 1.2 to 1.5 \\
\hline \multicolumn{6}{|l|}{ Depleted uranium } \\
\hline No & 1184 & 14.7 & (11.2) & 1.0 & - \\
\hline Yes & 218 & 14.2 & (10.0) & 1.0 & 0.9 to 1.1 \\
\hline \multicolumn{6}{|c|}{ 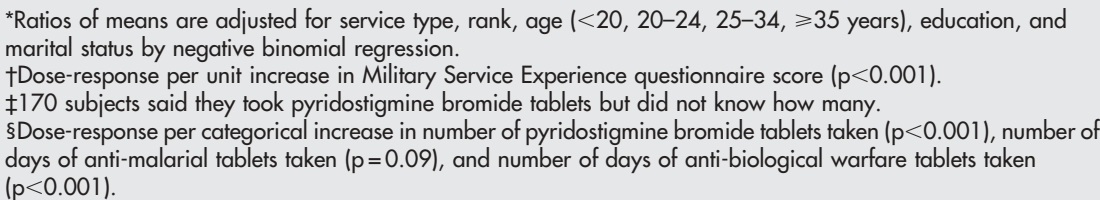 } \\
\hline
\end{tabular}

conditions. While back, neck, and other joint problems were the most commonly reported medical conditions in the Gulf War veterans, these were also the most commonly reported conditions in the comparison group, with little difference between the two study groups. The combination of selfreported health outcomes from a postal questionnaire with data obtained through a face-to-face medical assessment, allowed more objective assessment of self-reported medical conditions than previous research in this field.

Gulf War veterans do not appear to be over-reporting medical conditions or symptoms of a mild nature compared with the comparison group. Gulf War veterans are more likely to report symptoms that are more severe in nature and are about as likely to report medical conditions that were subsequently assessed as "possible" or "probable" diagnoses as the comparison group. A similar and high proportion (over $90 \%$ ) of medical conditions reported by both study groups were medically assessed as being "possible" or "probable" diagnoses, indicating a similar and small amount of over-reporting in both study groups. Our results show odds ratios typically less than two in magnitude, and mean number of symptoms in the order of $30 \%$ higher in Gulf War veterans than the comparison group. These figures still represent increases of substantive importance however.

Several previous studies have also found increased reporting of multiple symptoms by Gulf War veterans ${ }^{1246}$ and a similar ordering of symptoms reported by the Gulf War and their comparison groups. ${ }^{12}$ Symptoms most commonly reported by Gulf War veterans in our study are also among the symptoms most commonly reported by US, UK, and Danish Gulf War veterans. ${ }^{1245928}$ The use of different terminology and definitions for symptoms in the different studies can make comparisons difficult. However, the symptom questionnaire in our study was based on that used 
by Unwin and colleagues. ${ }^{1}$ A comparison of our results with their published data ${ }^{1}$ for these most common symptoms shows that the symptoms most commonly reported in both studies were similar. Our comparison group of non-deployed ADF personnel had higher symptom prevalences than the UK "Era" comparison group who were not deployed to either the Gulf War or Bosnia. The odds ratios (and also absolute difference in prevalences) for individual symptoms in our study were lower than those for the same symptoms in UK Gulf War veterans. We think that this finding probably relates more to the relatively higher prevalence of symptoms in our comparison group, than to the later timing of our study and any reduction in the differences between study groups over time.

In several other studies, the pattern of self-reported medical conditions has been similar to that of symptoms, with Gulf War veterans reporting many ${ }^{4}{ }^{6}$ or all $^{1}$ of the medical conditions more frequently than non-Gulf veterans. Again, the use of different terminology or definitions for medical conditions ${ }^{14}$ limits direct comparisons between studies, but there appears to be less similarity in the ordering of medical conditions between our study and that of Unwin and colleagues ${ }^{1}$ than was found for the ordering of symptoms.

We found that the difference between Gulf War veterans and the comparison group in the total number of symptoms reported was more marked in the younger age group $(<20$ years) and in those of lower rank. These differences did not differ significantly across the subgroups of age, rank, or service type. Increased symptom reporting has been found to be greater in younger veterans $(<25$ years $),{ }^{2}$ Army veterans, $^{24}$ and ranks other than officers. ${ }^{2}$ A strong association between rank and ill health has been reported in UK Gulf War veterans. ${ }^{29}$ We had relatively small numbers of Army and Air Force participants, which limited our ability to explore possible differences between the study groups for these service types.

Our finding of an association between having 10 or more immunisations and increased symptom reporting in Gulf War veterans is in general agreement with previous studies' findings of an association between multiple $(>6)$ immunisations and a multi-symptom illness, ${ }^{1}$ and number of immunisations and symptom severity score. ${ }^{3}$ We did not find having a cluster of immunisations to be associated with increased symptom reporting, although multiple immunisations during deployment has previously been found to be associated strongly with a multi-symptom illness. ${ }^{30}$ The total number of symptoms in our study was also greater in those who reported that they did not know the number of immunisations they received. The Gulf War veterans' uncertainty and the poor quality of the immunisation data makes it difficult to draw firm conclusions.

Our finding of an association between increased symptom reporting and taking anti-biological warfare tablets, or increasing numbers of anti-biological warfare tablets in a dose-response relation, has not been reported elsewhere. ${ }^{136}$ We found that increased symptom reporting was associated with increasing number of stressful Gulf War military service experiences in a strong dose-response relation. While some studies report associations with a limited range of specific individual experiences, such as feelings that life was in danger $^{3}$ or seeing dismembered bodies, ${ }^{1}$ these studies have not used a comprehensive measure of Gulf War related stressors to investigate the dose-response relation.

Some exposures that we found to be associated with increased symptom reporting have also been found in some of these other studies, although variation in outcomes reported, from symptom severity scores ${ }^{2}$ to symptom or instrument based definitions of medical and psychiatric conditions, ${ }^{16}$ limit direct comparisons. Our findings of an association with reportedly being in a chemical weapons area concurs with an association with belief of exposure to a chemical attack in UK veterans ${ }^{1}$ and exposure to chemical warfare agents in US veterans. ${ }^{6}$ Our finding of an association between pyridostigmine bromide tablets and exposure to pesticides and increased symptom reporting has also been reported in $\mathrm{UK}^{13}$ and US ${ }^{6}$ veterans. Lack of an association with antimalarial tablets has also been reported in relation to UK veterans. ${ }^{3}$

Many Gulf War exposures could have occurred together, and therefore attribution of a specific health outcome to a specific exposure is problematic. ${ }^{1367103132}$ One finding that argues against attributing adverse health outcomes in Gulf War veterans to a single specific medical, chemical, or environmental exposure is the association of increased symptom reporting with a number of Gulf War exposures. ${ }^{13} 6$

When considering the impact of these Gulf War exposures and experiences on health, it is important to remember that many studies relied on self-report, for which little, if any, objective documentation was available. Worsening selfperception of health (though not worsening physical health or psychological morbidity) over time in UK Gulf War veterans has been associated with increased reporting of Gulf War exposures. ${ }^{33}$ The reliability of recall of exposures, assessed using kappa ( $\kappa)$ as a measure of agreement, ${ }^{34}{ }^{35}$ has, however, varied for individual exposures. For example, smoke and oil from burning oil wells (SMOIL) was reliably recalled in both UK $(\kappa=0.79)^{33}$ and US $(\kappa=0.69)^{36}$ Gulf War veterans, and being given pyridostigmine bromide tablets was reliably recalled in US Gulf War veterans $(\kappa=0.86){ }^{36}$ Exposure to depleted uranium was poorly recalled in UK $(\kappa=0.48)^{33}$ and US $(\kappa=0.07)^{36}$ Gulf War veterans. In our study, self-reported exposure to depleted uranium was complemented by an algorithm based on location and activities during the Gulf War, to eliminate implausible exposure and further define the likelihood of possible exposure. In relation to immunisations, Gulf War veterans were asked to refer to their immunisation booklet. Veterans' uncertainty in relation to their medical exposures could have influenced our results. There are several reasons for this uncertainty, including the time that has elapsed since the Gulf War and poor record keeping at the time of the Gulf War. These aspects of exposure assessment highlights the importance of medical record keeping in the defence forces.

Recall bias may have occurred, ${ }^{37}$ whereby veterans who report symptoms or medical conditions are also more likely to recall more exposures, particularly those considered potentially harmful, than veterans who do not report adverse health outcomes. ${ }^{38}{ }^{39}$ Veterans who recall a specific exposure may also be more likely to associate their symptoms with exposure than those who did not. The effect of perception of vaccination on increased reporting of health outcomes has recently been reported in relation to the anthrax vaccine. ${ }^{40}$ In determining the year of first diagnosis, the Gulf War group had a well defined reference point, whereas the comparison group did not. Gulf War veterans may be more likely to date the development of any conditions post-Gulf War as this is a very prominent event for them, and this may have led to an overestimation of the association with medical outcomes. Another potential problem is that our analyses involved multiple comparisons and some of the significant associations that we observed could be due to chance alone.

Despite a rigorous and extended contact and recruitment strategy applied to both study groups, the participation rate in our comparison group was lower than that of the Gulf War veteran group. This has been the experience of other research groups. ${ }^{14910}$ The difference in participation rates contributed to some differences in the demographic composition of the 
two study groups, rendering the results of the study vulnerable to the effects of participation bias. Our formal evaluation of participation bias suggests that our study results may be robust despite some non-participation in the comparison group, and that participation bias is unlikely to explain the differences (or lack of differences) between the two groups in our study.

In conclusion, more than 10 years after the 1991 Gulf War, Australian Gulf War veterans report all symptoms and some medical conditions, including psychological (particularly post-traumatic stress disorder), skin, eye, and sinus conditions more commonly than a comparable group of ADF personnel who were eligible for active duty at the time, but did not go to the Gulf. Increased reporting of symptoms and medical conditions by Gulf War veterans does not appear to be due to over-reporting or participation bias. We have found associations between total number of self-reported symptoms in the past month and several exposures experienced in the Gulf War, including immunisations, prophylactic medications, chemical exposures, and stressful experiences during their deployment. There does not appear to be a unique single exposure associated with increased symptom reporting.

\section{ACKNOWLEDGEMENTS}

This study was funded by the Australian Government-Department of Veterans' Affairs, and was overseen by a Scientific Advisory Committee and by a Veterans' Consultative Forum, and we are grateful to members for their contributions and support. We acknowledge the contribution of Health Services Australia who conducted the medical assessments. We wish to thank the international researchers, in particular Professor Simon Wessely and Ms Catherine Unwin of the Gulf War Illness Research Unit, London, UK for their assistance and advice on the development of the study. We wish to thank Dr Keith Horsley, Dr Warren Harrex, Mr Bob Connolly, and his contact and recruitment team at DVA. Finally, and very importantly, we thank the Gulf War veterans and members of the comparison group for the time and effort they made to participate in the study.

\section{Authors' affiliations}

H L Kelsall, M R Sim, A B Forbes, D C Glass, D P McKenzie, J F Ikin,

M J Abramson, P Ittak, Department of Epidemiology and Preventive

Medicine, Monash University, Melbourne, Victoria, Australia

L Blizzard, Menzies Centre for Population Health Research, University of Tasmania, Hobart, Tasmania, Australia

\section{REFERENCES}

1 Unwin C, Blatchley N, Coker W, et al. Health of UK servicemen who served in Persian Gulf War. Lancet 1999;353:169-78.

2 Cherry N, Creed F, Silman A, et al. Health and exposures of United Kingdom Gulf war veterans. Part I: The pattern and extent of ill health. Occup Environ Med 2001;58:291-8.

3 Cherry N, Creed F, Silman A, et al. Health and exposures of United Kingdom Gulf war veterans. Part II: The relation of health to exposure. Occup Environ Med 2001;58:299-306.

4 Kang HK, Mahan CM, Lee KY, et al. Illnesses among United States veterans of the Gulf War: a population-based survey of 30,000 veterans. J Occup Environ Med 2000;42:491-501.

5 Fukuda K, Nisenbaum R, Stewart G, et al. Chronic multisymptom illness affecting Air Force veterans of the Gulf War. JAMA 1998;280:981-8.

6 The lowa Persian Gulf Study Group. Self-reported illness and health status among Gulf War veterans: a population-based study. JAMA 1997;277:238-45.

7 Proctor SP, Heeren T, White RF, et al. Health status of Persian Gulf War veterans: self-reported symptoms, environmental exposures and the effect of stress. Int J Epidemiol 1998;27:1000-10.

8 Steele L. Prevalence and patterns of Gulf War illness in Kansas veterans: association of symptoms with characteristics of person, place, and time of military service. Am J Epidemiol 2000;152:992-1002.
9 Ishoy T, Suadicani P, Guldager B, et al. State of health after deployment in the Persian Gulf. The Danish Gulf War Study. Dan Med Bull 1999;46:416-19.

10 Goss Gilroy Inc. Health study of Canadian Forces personnel involved in the 1991 conflict in the Persian Gulf, Ottawa, Canada, 1998.

11 Fulco CE, Liverman CT, Sox HC, eds. Gulf War and health: depleted uranium, pyridostigmine bromide, sarin, vaccines. Washington, DC: National Academy Press, 2000

12 Joseph SC, Comprehensive Clinical Evaluation Program Evaluation Team. A comprehensive clinical evaluation of 20,000 Persian Gulf War veterans. Mil Med 1997; 162:149-55.

13 Landrigan PJ. Illness in Gulf War veterans: causes and consequences [editorial]. JAMA 1997;277:259-61.

14 Kang HK, Natelson BH, Mahan CM, et al. Post-traumatic stress disorder and chronic fatigue syndrome-like illness among Gulf War veterans: a populationbased survey of 30,000 veterans. Am J Epidemiol 2003;157:141-8.

15 Ikin JF, Sim MR, Creamer MC, et al. War-related psychological stressors and risk of psychological disorders in Australian veterans of the 1991 Gulf War. Br J Psychiatry 2004;185:116-26.

16 Gallops M, Laufer RS, Yager T. The combat scale revised. In: Egendorf A, Kadushin C, Laufer RS, et al. Legacies of Vietnam: comparative adjustment of veterans and their peers. New York: Center for Policy Research, 1981:125-9.

17 Erickson DJ, Wolfe J, King DW, et al. Posttraumatic stress disorder and depression symptomatology in a sample of Gulf War veterans: a prospective analysis. J Consult Clin Psychol 2001;69:41-9.

18 Keane TM, Fairbank JA, Caddell JM, et al. Clinical evaluation of a measure to assess combat exposure. Psychological Assessment 1989;1:53-5.

19 Wolfe J, Brown PJ, Kelley JM. Reassessing war stress: exposure and the Persian Gulf War. Journal of Social Issues 1993;49:15-31.

20 Sutker PB, Davis JM, Uddo M, et al. War zone stress, personal resources, and PTSD in Persian Gulf War returnees. J Abnorm Psychol 1995;104:444-52.

21 Stata Statistical Software. Release 7.0. College Station, TX: Stata Corporation, 2001.

22 Hosmer DW, Lemeshow S. Applied logistic regression, 2nd edn. New York: Wiley, 2000

23 CYTEL. LogXact 4 for Windows, 4th version. Cambridge, MA: CYTEL Software Corporation, 2000.

24 Long JS. Regression models for categorical and limited dependent variables. Thousand Oaks, CA: Sage Publications, 1997.

25 McCullagh P, Nelder JA. Generalized linear models, 2nd edn. London: Chapman \& Hall, 1989

26 Ware JE, Kosinski M, Keller SD. A 12-item Short-Form Health Survey. Construction of scales and preliminary tests of reliability and validity. Med Care 1996:34:220-33.

27 Ware JE, Kosinski MA, Keller SD. SF-12: how to score the SF-12 physical and mental health summary scales, 3rd edn. Lincoln, RI: Quality Metric Incorporated, 1998.

28 Suadicani P, Ishoy T, Guldager B, et al. Determinants of long-term neuropsychological symptoms. The Danish Gulf War study. Dan Med Bull 1999:46:423-7.

29 Ismail K, Blatchley N, Hotopf M, et al. Occupational risk factors for ill health in Gulf veterans of the United Kingdom. J Epidemiol Community Health 2000;54:834-8.

30 Hotopf $M$, David A, Hull L, et al. Role of vaccinations as risk factors for ill health in veterans of the Gulf War: cross sectional study. BMJ 2000;320:1363-7.

31 White RF, Proctor SP, Heeren T, et al. Neuropsychological function in Gulf War veterans: relationships to self-reported toxicant exposures. Am J Ind Med 2001;40:42-54.

32 Reid S, Hotopf M, Hull L, et al. Multiple chemical sensitivity and chronic fatigue syndrome in British Gulf War veterans. Am J Epidemiol 2001;153:604-9.

33 Wessely S, Unwin C, Hotopf $M$, et al. Stability of recall of military hazards over time: evidence from the Persian Gulf War of 1991. Br J Psychiatry 2003;183:314-22.

34 Cohen J. A coefficient of agreement for nominal scales. Educational and Psychological Measurement 1960;20:37-46.

35 Kraemer HC, Periyakoil VS, Noda A. Kappa coefficients in medical research. Stat Med 2002;21:2109-29

36 McCauley LA, Joos SK, Spencer PS, et al. Strategies to assess validity of selfreported exposures during the Persian Gulf War. Environ Res 1999;81:195-205.

37 Joellenbeck LM, Landrigan PJ, Larson EL. Commentary: Gulf War veterans' illnesses: a case study in causal inference. Environ Res 1998;79:71-81.

38 Petruccelli BP, Goldenbaum M, Scott B, et al. Health effects of the 1991 Kuwait oil fires: a survey of US army troops. J Occup Environ Med 1999:41:433-9.

39 Rothman KJ, Greenland S. Modern epidemiology, 2nd edn. Philadelphia, PA: Lippincott-Raven, 1998.

40 Mahan CM, Kang HK, Dalager NA, et al. Anthrax vaccination and selfreported symptoms, functional status, and medical conditions in the National Health Survey of Gulf War era veterans and their families. Ann Epidemiol 2004; 14:81-8. 